\title{
IMPASSES NA CONSTITUIÇÃO DO SUJEITO CAUSADOS PELAS TECNOLOGIAS DIGITAIS
}

\section{Impasses in the Constitution of the Subject caused by Digital Technologies}

\section{Obstáculos en la Constitución del Sujeto causados por las Tecnologías Digitales}

\section{Impasses dans la Constitution du Sujet causées par les Technologies Numériques}

10.5020/23590777.rs.v20iEsp2.e8984

\section{Elzilaine Domingues Mendes 9 iD}

Professora de Psicologia da Universidade Federal de Catalão - UFCAT. Doutora em Psicologia Clínica e Cultura pela Universidade de Brasília.

\section{Resumo}

O objetivo deste artigo é refletir sobre a relação entre as tecnologias digitais e os seus efeitos na constituição do psiquismo. As transformações sociais e o desenvolvimento da tecnologia ampliaram as modalidades do brincar. As telas passaram a ocupar o lugar dos pais, o que tem colaborado para a fragilidade psíquica das crianças e para o aumento de psicopatologias, como atrasos no desenvolvimento da linguagem, dificuldades na socialização, obesidade, depressão, problemas de aprendizagem e dependência. Retomamos os escritos de Freud sobre a importância do brincar na constituição do sujeito, uma vez que, enquanto brinca, a criança elabora os seus conflitos e desenvolve a autonomia e a criatividade.

Palavras-chave: brincar; infância; telas; subjetividade; contemporaneidade.

\section{Abstract}

The purpose of this article is to reflect on the relationship between digital technologies and their effects on the constitution of the psyche. Social transformations and the development of technology have expanded the modalities of playing. The screens started to take the place of parents, which has contributed to the psychic fragility of children and the increase in psychopathologies, such as delays in language development, difficulties in socializing, obesity, depression, learning problems, and dependence. We resume Freud's writings on the importance of playing in the constitution of the subject, since, while playing, the child elaborates his conflicts and develops autonomy and creativity.

Keywords: play; childhood; screens; subjectivity; contemporaneity.

\section{Resumen}

El objetivo de este artículo es reflexionar sobre la relación entre las tecnologías digitales y sus efectos en la constitución del psiquismo. Las transformaciones sociales y el desarrollo de la tecnología ampliaron las modalidades del jugar. Las pantallas pasaron a ocupar el sitio de los padres, lo que ha colaborado para la fragilidad psíquica de los niños y para el incremento de psicopatologías, como retrasos en el desarrollo del lenguaje, dificultades en la socialización, obesidad, depresión, problemas de aprendizaje y dependencia. Reanudamos los escritos de Freud sobre la importancia del jugar en la constitución del sujeto, ya que, mientras juega, el niño elabora sus conflictos y desarrolla la autonomía y la creatividad.

Palabras clave: jugar; niñez; pantallas; subjetividad; contemporaneidad. 


\section{Résumé}

Le but de cet article est de réféchir sur la relation entre les technologies numériques et leurs effets sur la constitution de la psyché. Les transformations sociales et le développement de la technologie ont élargi les modalités de jeu. Les écrans ont commencé à substituer aux parents, ce qui a contribué à la fragilité psychique des enfants et à l'augmentation des psychopathologies, telles que les retards dans le développement du langage, les difficultés de socialisation, l'obésité, la dépression, les problèmes d'apprentissage et la dépendance. Nous revenons aux écrits de Freud sur l'importance du jeu dans la constitution du sujet, puisque, en jouant, l'enfant élabore ses conflits et développe son autonomie et sa créativité.

Mots-clés : jeu ; enfance ; écrans ; subjectivité ; contemporanéité.

As transformações sociais, econômicas e culturais interferem nos modos de subjetivação. Dentre os fatores que contribuem para esse processo podemos destacar as transformações nos laços sociais, como a passagem da família extensa para a família nuclear, a valorização do narcisismo, a televisão como condição de socialização e de subjetivação, a morte do sujeito freudiano, o sujeito da dúvida, crítico, e o surgimento de um novo sujeito precário, acrítico e incapaz de simbolizações (Dufour, 2004, 2005).

Além dessas transformações, nos deparamos com a revolução tecnológica que, segundo Nicolaci-da-Costa (2002), alterou a organização dos laços sociais, produzindo novas formas de constituição subjetiva. A autora faz uma comparação entre a Revolução Industrial e a revolução da tecnologia e diz que: “(...) tal como a primeira Revolução Industrial deu origem a um longo processo de mudanças que resultou na emergência do homem do século XX, a Revolução da Internet desencadeou um processo de transformações, ainda em curso, que está gerando o homem do século XXI" (Nicolaci-da-Costa, 2002, p. 199).

$\mathrm{O}$ uso das novas tecnologias de informação na infância modificou as formas de brincar e de se relacionar. Os objetos eletrônicos se tornaram novos brinquedos para as crianças, que passaram a ter contato com os aparelhos digitais, tais como tablets, smartphones, etc., em idades cada vez mais precoces, alterando as formas de brincar e de tempo livre, trazendo novas linguagens e novas necessidades de consumo (Froede, Wollz, Sousa, Sousa, \& Monteiro, 2014; Santos \& Barros, 2018).

A entrada da cultura midiática não substitui as brincadeiras infantis tradicionais. Foi o que constatou Ferreira (2015) ao realizar uma pesquisa de campo e observar que a criança incorpora nas brincadeiras tradicionais, que continuam sendo as suas prediletas, as brincadeiras da cultura em que vive. Desse modo, a cultura midiática é incorporada às brincadeiras infantis.

Podemos argumentar que os tempos são outros e que hoje, da mesma forma que os adultos, as crianças têm mais opções para utilizarem o seu tempo livre e se divertirem. Além disso, com o desenvolvimento tecnológico e científico, as formas de brincar foram ampliadas, o que pode ser constatado pela diversidade de brinquedos eletrônicos encontrados no mercado.

No entanto, ao refletirem sobre as transformações sociais ocorridas na infância, Bernardino e Kupfer (2008) chamam a atenção para o aparecimento de sintomas importantes, os quais dificultam o desenvolvimento das crianças, a exemplo da inibição do brincar, do aumento da agressividade e da falta de limites, relacionando esses problemas ao fracasso da autoridade paterna. Martins (2016) explica que o fato dos dispositivos eletrônicos serem oferecidos como brinquedos para as crianças em idade precoce traz impactos significativos na função constitutiva do brincar. Segundo Dunker (2017) e Jerusalinsky (2017a), o uso excessivo desses aparelhos traz consigo novas formas de sofrimento e mal-estar denominadas intoxicações eletrônicas. Esses sintomas nos fazem pensar que essas crianças sofrem em função de uma dificuldade de socialização, o que nos leva a questionar de que modo os aparelhos eletrônicos interferem na formação dos laços sociais e quais os efeitos do uso excessivo desses dispositivos na constituição do psiquismo.

Partimos da hipótese de que o uso indiscriminado dos aparelhos eletrônicos na primeira infância pode ser um dos fatores que dificulta a formação do vínculo parental e, consequentemente, do desenvolvimento da linguagem e da capacidade de simbolização. Nesse contexto, este artigo propõe-se a refletir sobre a relação entre as novas configurações do brincar e os seus efeitos na constituição do sujeito.

\section{A Infância na Contemporaneidade}

O fato de sermos falantes implica que não somos regidos apenas pelo que se passa em nosso corpo, pois, desde o nascimento, somos banhados pela linguagem. Nos Três ensaios sobre a teoria da sexualidade, Freud (1905/1996c) ampliou o conceito de sexualidade afirmando que o bebê experimenta sensações prazerosas já no início da vida. Trata-se de uma sexualidade perversa polimorfa, no sentido de que o prazer é parcial, provém das zonas erógenas e obedece às fases do desenvolvimento psicossexual. Portanto, o que nos torna sujeitos de linguagem é a passagem de um corpo biológico para um corpo erógeno, banhado pela linguagem e pela cultura. Segundo Lacan (1938/2003a), a família é a responsável pela 
transmissão da cultura e pela socialização. Assim, para compreendermos a infância na contemporaneidade, precisamos analisar as mudanças que se deram no interior das famílias e como elas interferem na organização do laço social e, ainda, até que ponto essas transformações afetam o desenvolvimento psíquico das crianças.

Roudinesco (2003) identifica três grandes períodos na evolução da família. Num primeiro momento, tivemos a família tradicional, cujo objetivo era assegurar a transmissão de um patrimônio. Nesse caso, os sentimentos do casal não eram tomados em consideração e predominava a autoridade patriarcal. Depois tivemos a família moderna, fundada no amor romântico, na reciprocidade dos sentimentos e desejos e na divisão do trabalho entre o casal. Esse modelo de família se impôs entre o final do século XVIII e meados do século XX. A partir dos anos 1960 temos a família contemporânea, caracterizada pela busca de relações íntimas ou realizações sexuais.

De acordo com Birman (2007), a figura da mulher/mãe estava destinada ao sacrifício em nome do investimento na educação da prole, enquanto a figura do pai estava relacionada ao espaço público. Contudo, com a inserção da mulher no mercado de trabalho, a mãe passou a sair de casa para trabalhar e os filhos passaram a ser educados também por terceiros (creches, escolas) e por babás. Vários acontecimentos contribuíram para as transformações na família, entre eles podemos ressaltar o início do movimento feminista em meados do século XX e o aparecimento do anticoncepcional. As mulheres passaram a pleitear outros lugares na sociedade, pois demandavam a igualdade entre os sexos. A criação da pílula anticoncepcional foi fundamental para a inserção da mulher no mercado de trabalho e para o controle da taxa de natalidade. As mulheres puderam, a partir daí, separar os registros do desejo do registro da reprodução, optando por ter ou não filhos, quando e quantos. Além disso, elas passaram a investir na capacitação intelectual, indo para as universidades e concorrendo de forma mais igualitária com os homens.

Se antes as mães se ocupavam diretamente do cuidado dos filhos, atualmente essa tarefa é compartilhada com outros. De acordo com Birman (2007), as mulheres passaram a colocar as suas carreiras na mesma posição que o casamento, o que mudou completamente o destino dos laços conjugais, aumentando as separações e as configurações familiares. As mulheres saíram de casa em busca da realização profissional, mas os homens não compensaram a ausência materna, o que faz com que as crianças ingressem nas creches e escolas cada vez mais cedo.

Atualmente, estamos diante de novas configurações familiares, que Kehl (2013) denomina de famílias tentaculares. São famílias formadas por casais héteros ou homossexuais, ou, ainda, famílias monoparentais, com ou sem filhos adotivos ou do novo cônjuge. Famílias em que os laços familiares independem da família de origem e nas quais as uniões são mantidas pelo desejo sexual. Nesse caso, os laços familiares são ampliados para além do casal parental, podendo incluir os casos de adoção, madrastas, padrastos, meios-irmãos etc.

Sabemos que a família tradicional, como já nos mostraram Freud (1893-1895/1996a) e Lacan (1938/2003a), não é a garantia de uma prole saudável. No entanto acreditamos que todas as mudanças relatadas por Roudinesco (2003), Birman (2007) e Kehl (2013) interferem no lugar que a criança passa a ocupar nas famílias e na sociedade. Para Birman (2007, 2012) essas transformações nos laços sociais tiveram como consequência um desinvestimento narcísico - primeiro, na infância e depois, na adolescência -, possibilitando o surgimento de novas modalidades de subjetivação e de psicopatologias que se inscrevem no registro do corpo, da ação e das intensidades. $O$ fato das mulheres saírem de casa para o mercado de trabalho e os homens não se responsabilizarem pelo cuidado com os filhos, compensando a ausência materna, como aponta Birman (2007), deixa as crianças mais vulneráveis, uma vez que isso faz com que as mulheres aumentem a sua carga de trabalho e passem a disponibilizar um tempo menor para o cuidado dos filhos, o que, sem dúvida, pode trazer alterações nas formas de subjetivação.

Já em relação às novas configurações familiares, acreditamos que elas não chegam a prejudicar o desenvolvimento das crianças e adolescentes, pois mais importante do que os laços consanguíneos são os laços afetivos que se estabelecem entre as crianças e aqueles que delas cuidam. Essas novas configurações sociais podem, inclusive, ampliar os laços sociais.

Para Lacan (1938/2003a), a família é a instituição mais importante no desenvolvimento emocional da criança, pois é na família que se dá as primeiras relações do bebê. Nesse contexto, o sujeito é falado mesmo antes do seu nascimento. Em Nota sobre a criança, Lacan (1961/2003b) explica a importância das funções materna e paterna na constituição do sujeito. Quando Lacan fala de função materna e função paterna ele não está falando de diferenças biológicas ou sexuais. Ele se refere às operações de alienação e separação que são essenciais na constituição subjetiva e que são exercidas, respectivamente, por quem faz função de mãe e de pai. É a partir do grande Outro que o sujeito se constitui. Nesse processo, quem faz função de mãe se configura como o Outro para a criança. Assim, cabe a quem faz a função materna apresentar e interpretar o mundo para o bebê, emprestar sentidos e significados à criança. Já a função paterna é responsável pela mediação da relação da mãe com a criança, introduzindo a lei, ou seja, a função paterna é responsável pela separação da criança da mãe, pela interdição do incesto, o que possibilita que a criança se depare com a falta e, consequentemente, com o seu próprio desejo. São essas operações que vão garantir a constituição do sujeito. Por outro lado, se há falhas nessas operações, podemos nos deparar com impasses na constituição subjetiva. Assim, compreendemos que mais importante do que os laços consanguíneos são as operações de alienação e de separação que fundamentam a constituição psíquica. 
Aliado às novas composições familiares, temos os avanços tecnológicos, especialmente o desenvolvimento dos dispositivos eletrônicos, cada vez mais sofisticados, que possibilitam também novas formas de brincar e de estar com o outro, que independem da presença física, uma vez que são aparelhos "sem fronteiras", que desafiam a realidade espacial e temporal. Todas essas transformações nos levam a questionar os seus efeitos na constituição psíquica, principalmente nas crianças menores de três anos.

\section{A Influência das Tecnologias Digitais na Constituição do Sujeito}

Com as transformações na dinâmica familiar, os pais têm cada vez menos tempo para dar atenção aos filhos. Esse desinvestimento narcísico contribui para a solidão infantil e, consequentemente, para a fragilidade do sujeito. Esses fatores colaboram para que as crianças passem cada vez mais tempo diante da televisão, do smartphone e dos jogos eletrônicos, a ponto desses aparelhos passarem a ocupar um lugar especial na vida dos pequenos, lugar anteriormente destinado aos pais.

De acordo com Dufour (2004), a família contemporânea ganha um novo agregado, que ele denomina um terceiro pai: a televisão. Em seu artigo, Dufour (2004) traz reflexões acerca do lugar da televisão na vida das crianças e sobre a sua influência na constituição da subjetividade. A televisão tem ocupado o papel dos pais na contemporaneidade, uma vez que as crianças têm passado mais tempo assistindo à televisão do que convivendo com seus próprios pais, pois elas ficam um terço de seu tempo junto à televisão. Além disso, a televisão está em todos os espaços privados, como salas, quartos etc. A televisão em cada quarto satisfaz a cada um, mas ao preço de evitar todo debate e toda discussão familiar. É uma democracia sem discurso nem discussão.

As crianças estão expostas desde bebês a um turbilhão de propagandas de publicidade, que incentivam cada vez mais o consumo. Mas o problema não é somente o desejo de adquirir um objeto, uma marca, mas as referências que passam a ocupar o lugar da família clássica. Nesse caso, as transformações produzidas na família pela televisão causam uma desregulação no acesso ao simbólico, produzida pelo imaginário televisual. Há um desmoronamento da família clássica, uma vez que a televisão passa a funcionar como terceiro pai, pois a família real é substituída pela família virtual. A televisão também substitui a literatura, o livro.

Dufour $(2004,2005)$ argumenta que a televisão traz consequências devastadoras para a formação da criança, uma vez que não existem trocas subjetivas entre a criança e a televisão. A criança ocupa um lugar passivo diante da televisão, um lugar de telespectadora. A inundação do espaço infantil pela mídia, com um fluxo ininterrupto de imagens e sons, tem efeitos consideráveis sobre a formação do sujeito falante. Perturbações semióticas são produzidas pela exposição prematura e massiva da criança à imagem televisiva, o que pode gerar sujeitos mal instalados no discurso.

Na espécie humana, a transmissão da linguagem se dá a partir do contato com o outro. Para Lacan (1938/2003a), a família desempenha um papel primordial na transmissão da cultura e da linguagem, uma vez que "a família prevalece na educação precoce, na repressão dos instintos e na aquisição da língua legitimamente chamada materna” (p. 25). Segundo Lacan, são necessárias duas operações para a entrada na linguagem, a alienação e a separação. Na alienação, antes que o eu afirme a sua identidade, ele se confunde com a imagem que o forma, com quem faz a função materna. A separação implica a introdução de um terceiro, que substitui essa confusão afetiva e a ambiguidade especular pela concorrência de uma situação triangular. São operações que demandam tempo e convivência, e que implicam numa troca afetiva entre a criança e aqueles que fazem as funções parentais.

Nesse sentido, é preciso estar com o bebê, compartilhar das suas experiências, para transmitir sentido e significados. Só assim é possível sustentar a transmissão das palavras, da linguagem e dar sentido às suas experiências. A partir dessas operações é que a criança desenvolve a linguagem, a sua capacidade de simbolização e de interação com aqueles que a cercam.

Podemos, então, inferir que a exposição indiscriminada da criança à televisão pode interferir e até atrasar a aquisição da linguagem, da capacidade simbólica e de interação social. A transmissão do dom da palavra na espécie pode ser alterada. Sabemos que a simbolização se opera pela simples colocação em obra da mais velha atividade humana, o discurso oral face a face. É por meio da fala que a criança tem acesso aos indicadores de pessoa (eu, tu, ele), de tempo (agora, hoje, ontem) e de espaço (aqui, lá, outro lugar). A televisão funciona como mídia não endereçada, ela não interpela e não obriga a responder. Ela escapa, assim, à obrigação simbólica fundamental da reciprocidade, estabelecendo que um fala e o outro tem que responder.

Dessa forma, concordamos com Dufour $(2004,2005)$ que a exposição excessiva da criança pequena diante da televisão pode produzir sujeitos mal instalados no discurso, sem referências simbólicas de pessoas, tempo e lugar. Nesse caso, o problema não seria a televisão, mas a exposição precoce e solitária de um sujeito ainda em constituição e que necessita, nesse estágio do seu desenvolvimento, de outro que interaja com ele e lhe empreste significantes para a compreensão do que se passa ao seu redor. Quando as referências do discurso já estão colocadas, a criança pode acolher as imagens, mesmo sendo elas violentas. Nesse caso, o vai e vem das imagens pode até ser lúdico e formador, uma vez que o sujeito tem condições de elaborá-las. Se o sujeito se coloca no discurso, ele não passa ao ato.

A questão dos agregados familiares tem se ampliado significativamente, pois, além dos televisores, outros dispositivos dotados de telas passaram a ter um papel central na vida das crianças, expondo-as ao mundo digital cada vez mais cedo. 
Assistimos, cada vez mais, crianças pequenas usarem esses aparelhos eletrônicos como brinquedos e entretenimento com o consentimento e alívio dos pais. Podemos nos perguntar qual o lugar simbólico desses dispositivos eletrônicos na vida das crianças, especialmente dos bebês. As crianças parecem gostar deste tipo de "brinquedo" e, quando eles lhes são retirados, elas ficam irritadas e até choram. Esses aparelhos são as novas babás eletrônicas, muito funcionais para os pais, pois, enquanto brincam com esses dispositivos, as crianças permanecem quietas e os pais podem descansar ou trabalhar. Mas quais os efeitos desse tipo de entretenimento para as crianças? Até que ponto o uso precoce e indiscriminado das telas interfere no desenvolvimento da capacidade de simbolização?

De acordo com Dufour (2004), a televisão traz prejuízos para a constituição do sujeito, principalmente se a criança é exposta a ela em idades muito precoces. Podemos afirmar que, além dos prejuízos relacionados ao uso da televisão, o uso dos tablets e smartphones por bebês também pode prejudicar a sua formação subjetiva, principalmente o desenvolvimento da linguagem e da capacidade simbólica. Se a televisão está em todos os ambientes, os tablets e smartphones estão intensamente presentes na vida das crianças, pois eles são objetos móveis, ou seja, podem ser transportados juntos com as crianças para qualquer lugar.

Além disso, o uso dos aparelhos eletrônicos e das redes sociais acaba interferindo nos laços sociais, pois, como explica Dufour (2004), com a utilização desses dispositivos não há outro que intervenha entre o aparelho e a criança, o que impossibilita que haja uma verdadeira comunicação. Podemos acrescentar que as crianças e adolescentes passam horas nas redes sociais, no Instagram, no Facebook ou no WhatsApp, se comunicando por meio da tela. Esse excesso de conexão faz com que as pessoas, mesmo estando juntas no mesmo ambiente, se desliguem daqueles que estão presentes e se conectem com os que estão distantes. Por um lado, podemos pensar que essas novas formas de comunicação colaboram para uma maior interatividade entre as pessoas, mesmo quando elas estão distantes, mas, por outro lado, diminuem o contato e a convivência entre os próprios familiares, uma vez que estão todos juntos, na mesma casa, porém cada um com o seu aparelho, isolado em seu quarto.

Jerusalinsky (2017a) explica que o uso dos aparelhos eletrônicos na primeira infância tem contribuído para aumentar os diagnósticos de transtorno do espectro autista e síndrome de Asperger, o que, segundo a autora, representa uma confusão de diagnósticos de autismo com diagnósticos de atrasos na linguagem e de atrasos cognitivos. Ademais, Jerusalinsky (2017b) sustenta que muitas das crianças que recebem o diagnóstico de transtorno do espectro autista (TEA), na verdade, sofrem de intoxicações eletrônicas. São crianças que desde muito cedo têm suspensos o seu contato com o outro, sendo capturadas pelas telas eletrônicas e por personagens virtuais, o que pode causar atrasos na aquisição da linguagem. Esses aparelhos não demandam nada da criança, então ela logo percebe que o que o eletrônico quer é apenas a repetição, daí ela passa a repetir aquilo que ouve como um autômato. Os smartphones e os tablets emitem sequências sonoras, mas não conversam; eles reagem aos gestos do bebê e não às palavras. Nesse caso, as crianças repetem os sons emitidos pelos aparelhos eletrônicos, sons desprovidos de significados, pois não há uma fala desejante nesses dispositivos. Assim, os eletrônicos passam a ocupar o lugar do Outro para essas crianças. Sabemos que, no início da vida, é quem faz a função materna que sustenta a instauração do funcionamento corporal, na medida em que apresenta e interpreta o mundo para o bebê. Podemos argumentar que o problema maior se dá quando a criança tem acesso a aparelhos quando ela ainda está em constituição e é deixada por muito tempo diante da televisão, do celular ou dos jogos eletrônicos. Quando ela passa a ter como seu maior interlocutor a tela, principalmente se ela é ainda muito pequena, se não tem outras referências parentais, a ponto de serem facilmente substituídas pelas imagens televisivas ou eletrônicas. Assim, se o contato com o outro é substituído pelo contato com os eletrônicos, a criança pode apresentar problemas no decorrer do seu desenvolvimento ou ainda riscos na sua constituição subjetiva. $\mathrm{O}$ problema é agravado quando a interação com esses aparelhos é substituída pela interação parental e, posteriormente, pela interação social. Quando a criança perde o interesse pela exploração do ambiente em que vive e pelas atividades físicas. Quando as crianças e/ou adolescentes preferem ficar sozinhas com seus aparelhos, sem a presença do outro.

Em relação à querela dos diagnósticos de autismo, Ferreira e Vorcaro (2017) explicam que é muito difícil falar da quantidade de casos detectados ou de um aumento de casos de autismo na contemporaneidade, uma vez que, "num mesmo 'balaio', muitos quadros heterogêneos e complexos são depositados, dificultando cada vez mais o acertado diagnóstico" (p.69). Nesse contexto, podemos dizer que, como constatam Ferreira e Vorcaro (2017) e Jerusalinsky (2017a), nem todo o sofrimento psíquico na primeira infância é autismo. Atrasos no desenvolvimento da linguagem e da cognição e dificuldades de socialização não são sintomas suficientes para o diagnóstico de autismo. São sintomas importantes que podem significar problemas no desenvolvimento infantil.

Preocupados com a irrupção da informática nos últimos dez anos, a França publicou um documento da Academia de Ciências, redigido por Bach, Houdé, Léna, e Tisseron (2013), intitulado L'enfant et les écrans: Un Avis de L'Académie des Sciences, que se propõe a refletir sobre os pontos positivos e negativos decorrentes do uso das telas por crianças e adolescentes. Em relação aos efeitos positivos, temos a melhora na aquisição de conhecimentos, contribuindo na formação do pensamento e na inserção social de crianças e adolescentes. No entanto a utilização desmesurada de todas as modalidades digitais (jogos virtuais, Internet, telefone portátil, tablets, smartphones, redes sociais etc.) pode ter efeitos graves e até irreversíveis. Os efeitos nefastos ligados à utilização muito precoce das telas ou a um uso indiscriminado, como o excesso de tempo passado diante dos aparelhos 
eletrônicos, está na origem de problemas de concentração, falta de sono e a eliminação de outras formas de cultura. De outra parte, existem os efeitos patológicos, como a obesidade, a depressão, as lesões nos tendões e na visão, as adições às telas etc.

Em função dos problemas e riscos que a presença da tecnologia digital tem acarretado na vida das crianças, Bach et al. (2013) fazem um alerta à sociedade e propõem algumas recomendações para a Academia de Ciências da França, que aconselha uma educação progressiva às telas digitais, adaptadas a cada idade, levando em conta a fase de desenvolvimento das crianças e adolescentes e organizada pelos pais e professores. Em 2018, Serge Tisseron, psicanalista francês, propôs La règle 3-69-12, que diz respeito a algumas regras para a exposição dos jovens às telas. Para Tisseron (2018), antes de três anos não é recomendável o uso dos aparelhos eletrônicos, uma vez que a criança precisa interagir com o seu meio utilizando os cinco sentidos (audição, visão, tato, olfato e paladar). A criança tem necessidade, antes dos seis anos, de criar com os seus dez dedos e de construir uma representação do espaço em três dimensões. É necessário oferecer tempo para a criança brincar e imaginar utilizando os dedos e as mãos. A partir dos nove anos, a criança tem necessidade de ser acompanhada para descobrir a Internet com segurança. Devemos mostrar a ela a utilidade dessa ferramenta, mas também os seus limites e perigos. A partir dos doze anos, a criança pode ter acesso à Internet, mas não a qualquer hora nem qualquer site, e de preferência não no seu quarto. De qualquer forma, ela deve ser acompanhada por um responsável e o uso das telas não pode substituir a interação social.

Assim, para Bach et al. (2013), Dufour (2004), Jerusalinsky (2017a, 2017b) e Tisseron (2018), o problema não é o uso dos eletrônicos, mas a idade em que a criança é exposta a esses dispositivos e o tempo que ela permanece em contato com eles em detrimento do contato com outras pessoas. Antes dos três anos de idade, as crianças não têm necessidade dos aparelhos eletrônicos, pois elas precisam estar em contato com outras pessoas, principalmente com alguém que exerça a função materna. Além disso, as crianças precisam explorar o meio no qual vivem, desenvolver a motricidade, a linguagem e a capacidade simbólica.

Mas por que será que precisamos estabelecer regras para o uso dos dispositivos eletrônicos? E porque as crianças e adolescentes ficam tanto tempo com esses aparelhos? A evolução da tecnologia e do mundo digital, além de ser algo fascinante para adultos e crianças, faz parte do mundo contemporâneo, e a nossa convivência com as telas parece ser necessária e inevitável.

Para Buzyn (2009), na sociedade contemporânea, os pais têm muita dificuldade para colocar limites nos filhos, o que pode estar relacionado às transformações sociais, sobretudo no interior das famílias. Na maior parte das vezes, os pais se sentem culpados pelo pouco tempo dedicado aos filhos e acabam compensando essa falta com presentes e, muitas vezes, acabam sendo mais permissivos. No entanto o limite é essencial para o desenvolvimento emocional e se constitui como uma prova de amor aos pequenos. Como afirma Lacan (1938/2003a), o limite faz parte da função paterna, é essencial na constituição do sujeito. Quando a criança cresce sem limites, pode haver uma falha na operação de separação, o que implica que não haverá o outro para interferir e contribuir para a ascensão da criança enquanto um ser de falta, de desejo.

Assim, o que observamos hoje é um uso excessivo e ilimitado das telas por crianças e adolescentes e, na maior parte das vezes, com o consentimento dos pais e sem a supervisão dos adultos. Diante desses fatos, o brincar tradicional perde espaço para a Internet e para os jogos eletrônicos. Os jovens ficam fascinados com o mundo digital e não conseguem ter um tempo livre para si mesmo. Como consequência, ficam viciados na Internet, nos jogos, celulares e nas séries televisivas, e não encontram tempo para as brincadeiras tradicionais nem para a convivência com o outro. Dessa forma, não conseguem lidar com o tédio, a tristeza, o não fazer nada, que consideramos extremamente criativos e saudáveis. Han (2017) afirma que o excesso de estímulos, informações e impulsos modifica racionalmente a estrutura e a economia da atenção, e o processamento e elaboração das informações. A rápida mudança de foco entre diversas atividades, fontes informativas e processos reduz a capacidade de atenção e de reflexão profunda, e impede, ainda, que a pessoa vivencie o tédio que é essencial para o processo criativo.

Observamos que as transformações no interior das famílias, aliadas ao uso excessivo dos aparelhos eletrônicos em idade cada vez mais precoce, têm colaborado para a precarização do sujeito, trazendo prejuízos para a constituição psíquica. Além disso, a fragilidade dos laços sociais, a falta de interação das crianças pequenas, principalmente dos bebês com os pais, pode implicar num atraso no desenvolvimento da linguagem, da capacidade de concentração, de socialização e de problemas de comportamento, que, como aponta Jerusalinsky (2017a) pode ser confundido com diagnósticos de autismo. Se, por um lado, esses tipos de jogos fascinam as crianças; por outro lado, também retiram dela o tempo do ócio que leva à criatividade e ao brincar tradicional, que, como veremos a seguir, é extremamente importante para a elaboração de conflitos. Nesse sentido, faz-se necessário resgatar a importância e a função do brincar no desenvolvimento das crianças.

\section{A Importância do Brincar na Constituição do Psiquismo}

Ao escutar as histéricas, Freud (1893-1895/1996a) percebe que seus sofrimentos estão vinculados ao passado mais remoto, o que o leva a buscar na infância as explicações para a compreensão dos processos psíquicos. Freud (1905/1996c, 1920/2006) começa, então, a se interessar pela observação das crianças, especialmente pelo brincar. 
De acordo com Freud (1908[1907]/1996d, 1920/2006), o desenvolvimento emocional da criança depende da sua capacidade de brincar, de fantasiar e de se relacionar com o outro. E aprender a brincar se dá a partir do contato com o outro, ou seja, a partir das primeiras relações que a criança estabelece com quem faz a função materna, pois, como dito anteriormente, a família é responsável pela transmissão da cultura e é na família que se inicia o processo de socialização da criança.

Freud (1908[1907]/1996d) afirma que, enquanto brinca, a criança cria um mundo de fantasia, no qual ela brinca de ser "gente grande" (imita os pais, os professores), realiza o seu desejo de controlar a própria vida. Nesse sentido, o brincar pode ser comparado aos sonhos, sendo que ambos são, como Freud (1899-1900/1996b) aponta, realizações de desejos. Além disso, o brincar é uma forma natural que a criança tem de buscar seu próprio desejo e se desvencilhar dos desejos parentais. Uma maneira autêntica de se constituir como um sujeito, dono de seu próprio desejo.

Em 1920, Freud (1920/2006) estuda como o aparelho psíquico opera por meio da brincadeira infantil. Entre os motivos do brincar da criança, Freud aponta para os ganhos prazerosos de tais atividades. Ao observar a brincadeira repetitiva de uma criança de um ano e meio que, na ausência da mãe, não chorava, mas jogava longe os seus brinquedos e dizia fort (foi) e, que quando eles reapareciam, ela murmurava $d a$ (está aqui), Freud compreende que essa brincadeira, às vezes cansativa e repetitiva, se constituía para a criança numa fonte de prazer. Freud se questiona porque a criança repete como brincadeira algo que a faz sofrer e chega à conclusão de que essa atividade é uma tentativa da criança de elaborar o conflito provocado pela ausência da mãe. Nesse caso, a criança transformou a vivência dolorosa em uma brincadeira.

O que Freud nos ajuda a compreender a partir dessa experiência do Fort-Da é a importância da alternância entre a presença e a ausência da mãe para a construção da capacidade de simbolização. Esse espaço vazio deixado pela ausência da mãe possibilita que a criança possa repetir, por meio do brincar, a experiência dolorosa e criar outras possibilidades, mais prazerosas para lidar com essa ausência. Assim, as pequenas ausências da mãe fazem com que a criança comece a lidar com a falta, quando passa a perceber que a mãe tem outros interesses além dela (criança), o que permite que ela saia da alienação com a mãe e vá em busca do seu próprio desejo, o que dá início ao processo de separação.

Trovão de Queiroz (2019), ao questionar sobre o uso de gadgets na primeira infância, declara que esses objetos, normalmente, são ofertados na tenra idade para que o bebê aprenda a tolerar as ausências do cuidador sem chorar ou se angustiar. Assim, esses objetos são utilizados para preencher o tempo de espera da criança quando o cuidador precisa se ausentar, o que pode prender a sua atenção e inclusive apaziguá-la. No entanto esse tempo de espera, gerado pela ausência materna, é extremamente importante para que a criança perceba a falta e crie possibilidades de lidar com ela. Essa ausência é necessária para a entrada da criança no campo simbólico. O fato dos aparelhos estarem disponíveis o tempo todo faz com que eles substituam o papel do grande Outro, respondendo à demanda do sujeito, o que pode fazer com que a criança passe a não desejar a presença do outro. E, como vimos anteriormente, o sujeito se constitui a partir da relação com o outro.

Não devemos ignorar o prazer contido no ato de brincar, mas devemos refletir sobre a repetição da brincadeira mesmo quando nela está presente uma vivência dolorosa, como no caso da criança observada por Freud, que repetia incansavelmente, por meio da brincadeira, a ausência da mãe. Para Freud (1920/2006), existe na vida psíquica uma compulsão à repetição que ultrapassa o princípio de prazer. Essa compulsão está presente nos sonhos, na transferência e no brincar.

No caso da brincadeira, Freud (1920/2006) pontua ainda que temos que considerar a atividade lúdica como uma tendência que está além do princípio do prazer, talvez como uma tentativa de elaboração de um conflito. Ao repetir uma vivência traumática, a criança passa do estado de passividade para uma condição ativa, na qual ela passa a comandar, a exercer o seu poder, o que possibilita a elaboração de um conflito. Assim, no brincar, criança encontra meios de transformar uma experiência desprazerosa em objeto de recordação e processamento psíquico.

Podemos comparar o brincar com os sonhos. Se nos sonhos noturnos a criança realiza os seus desejos, no brincar, ela elabora os problemas vivenciados no seu dia a dia. Por meio da fantasia é que ela realiza os seus desejos. Assim, a fantasia é uma forma de sonhar acordado ("sonhos diurnos", "devaneios"). No brincar, a criança também realiza os seus desejos, porém aqui ela os expressa de uma forma espontânea, sem repressão. Quando cresce, o adulto para de brincar, porque se envergonha das suas fantasias. Os sonhos nas neuroses traumáticas não são realizações de desejo. Esses sonhos obedecem à compulsão à repetição. A função da compulsão à repetição faz ressurgir aquilo que foi recalcado. Algumas brincadeiras, que acreditamos serem traumáticas e se repetem não são realizações de desejos, são tentativas de fazer ressurgir aquilo que foi esquecido e recalcado (Freud, 1920/2006).

De acordo com Winnicott (1971/1975), "É no brincar, e somente no brincar, que o indivíduo, criança ou adulto, pode ser criativo e utilizar sua personalidade integral: e é somente sendo criativo que o indivíduo descobre o eu (self)" (p. 80). Winnicott (1971/1975) também analisa a importância da relação mãe-bebê na formação subjetiva da criança, na inserção da linguagem e do desenvolvimento da capacidade de criar/brincar. Para Winnicott, é a partir do contato com o outro, especialmente quem faz função de mãe, que o bebê desenvolve a sua capacidade de brincar, o seu potencial criativo. É necessário que alguém interaja com a criança, se relacione com ela, apresente-a ao mundo, para que ela tenha acesso ao mundo simbólico e desenvolva as suas potencialidades, como a linguagem, a criatividade e a capacidade de interação social. 
Freud (1920/2006) e Winnicott (1971/1975) afirmam que o brincar está presente na vida dos bebês. O brincar faz parte do desenvolvimento da função simbólica. Para Freud (1908[1907]/1996d), a atividade lúdica é mais próxima dos devaneios e da criação artística. Winnicott (1971/1975) revela a importância do objeto transicional para que a criança seja capaz de suportar a ausência materna, e Freud (1920/2006) percebe que a criança representa, por meio da brincadeira, os conflitos vivenciados com a ausência da mãe. Assim, a criança, por meio do jogo lúdico, transforma uma situação desprazerosa, a ausência da mãe vivida de forma passiva, em uma vivência menos angustiante, uma vez que, repetida de forma ativa. A repetição, como aponta Freud (1920/2006), é a essência do brincar. A criança repete na tentativa de elaborar os seus conflitos.

Tanto Freud (1908[1907]/1996d, 1920/2006) quanto Winnicott (1971/1975) afirmam que o brincar é fundamental para o desenvolvimento psíquico da criança, pois além de desenvolver o psiquismo, a autonomia e a criatividade, ajudam a criança a elaborar os seus conflitos. De acordo com Freud (1908[1907]/1996d), toda criança que está bem brinca. E para nós, psicanalistas, se a criança para de brincar, consideramos que ela não está bem. $\mathrm{O}$ não brincar é um sintoma, uma forma de expressão que nos indica que a criança está sofrendo.

\section{Considerações Finais}

O desenvolvimento das tecnologias digitais que traz para o mercado e para os lares, de forma intensa e acelerada, o uso de aparelhos eletrônicos cada vez mais sofisticados, primeiro pelos adultos e depois pelas crianças e adolescentes, traz mudanças significativas no interior dos lares e nas formas de interação social, inclusive no brincar.

Vivemos, atualmente, imersos no mundo da Internet, e as crianças e adolescentes nascem nesse mundo, ou seja, o acesso aos eletrônicos e à Internet acontece cada vez mais cedo e de forma intensa na vida das crianças e adolescentes. É uma evolução que parece irreversível, por isso temos que conviver com ela. Sabemos dos seus efeitos positivos, como a melhora na aquisição de conhecimentos e também na contribuição para a formação do pensamento e para a inserção social de crianças e adolescentes. No entanto uma utilização precoce pode ter consequências perigosas e irreversíveis para a criança, pois pode colocar em risco o seu desenvolvimento psíquico.

Nos primeiros anos de vida, as crianças, especialmente os bebês, precisam de alguém que interaja com eles. Essa interação é a base para a constituição do sujeito. Sabemos que a constituição psíquica se dá por meio do Outro, de alguém que faça a função de mãe, que apresente o mundo para esse sujeito, que dê significantes para as suas experiências. Nesse sentido, os eletrônicos podem gerar sofrimento para aqueles que ainda não têm as referências simbólicas bem fixadas. A sua introdução precoce pode suspender ou privar o contato da criança com o outro, tão importante no seu desenvolvimento psíquico. Esse outro que vai marcá-la com a falta, a partir da qual o desejo poderá advir. Assim, concluímos que a fragilidade nos laços sociais, aliada à falta de interação da criança pequena, principalmente dos bebês com os adultos, pode implicar num atraso na aquisição da linguagem, em dificuldades de concentração, em problemas de comportamento e no desenvolvimento da capacidade de simbolização, que, como vimos anteriormente, pode ser confundido com o diagnóstico de autismo. Mesmo em idades mais avançadas, o uso das telas pode originar problemas duradouros para a saúde das crianças, como perturbações na concentração, obesidade, insônia, tendinites, problemas de aprendizagem, adições etc. Além disso, o uso maciço dos aparelhos eletrônicos pode deixar a criança passiva e submissa.

Ressaltamos que o brincar é extremamente importante no desenvolvimento físico e emocional das crianças. Quanto mais elas brincam, mais elas se desenvolvem de forma saudável. No entanto o brincar é mais importante do que o brinquedo, sobretudo o brincar com o outro, com a mãe, o pai, os irmãos ou outros colegas. A convivência com outras crianças é essencial para a socialização. É brincando que a criança aprende a dividir, a respeitar o outro, a internalizar as regras sociais, a elaborar os seus conflitos, a lidar com as frustrações, e desenvolve a criatividade, a autonomia etc. Enfim, é a partir do contato com o outro que a criança desenvolve a subjetividade, torna-se sujeito do seu próprio desejo. Nesse sentido, é preciso tempo para estar com as crianças e adolescentes.

Como ressaltamos anteriormente, as tecnologias ampliaram as formas do brincar, trazendo consigo objetos fascinantes e capazes de transformar as nossas redes de contato e, inclusive, o nosso conhecimento. As novas tecnologias revolucionaram nossos modos de relacionamento e trouxeram também novos modos de subjetivação. Todas essas transformações ainda são para todos nós muito recentes, ainda nos assustam e nos surpreendem. Elas estão aí, fazem parte do nosso mundo e, com certeza, melhoraram muito a nossa vida, mas também trouxeram novos sintomas que nos desafiam, e cabe a nós, psicanalistas, compreendermos os sofrimentos da nossa época. Assim, acreditamos que as tecnologias podem ser utilizadas como aliadas no processo de ensino-aprendizagem se respeitando as fases do desenvolvimento infanto-juvenil, ampliando o seu repertório cultural e suas possibilidades de expressão. Além disso, ressaltamos a importância de um tempo para o brincar livre. Não devemos esperar o tempo todo que o brincar sirva para o desenvolvimento cognitivo ou que ele seja usado apenas para alcançar esse objetivo, pois não é essa a sua função. Brincar é ter a liberdade para sonhar, para criar alternativas mais prazerosas para a vida. 
Não pretendemos esgotar o tema em questão, pois se trata de um assunto polêmico e complexo, uma vez que nossas experiências com o mundo digital ainda são muito recentes. Os efeitos dessas transformações na constituição subjetiva das nossas crianças, especialmente na capacidade simbólica, necessitam de tempo para serem apreendidos. Além disso, temos que considerar que os avanços da Inteligência Artificial ainda podem nos trazer inúmeras surpresas.

\section{Referências}

Bach, J. F., Houdé, O., Léna, P., \& Tisseron, S. (2013). L'enfant et les écrans: Un Avis de L'Académie des Sciences. Paris: Le Premier. Link

Bernardino, L. M. F., \& Kupfer, M. C. M. (2008). A criança como mestre do gozo da família atual: desdobramentos da "pesquisa de indicadores clínicos de risco para o desenvolvimento infantil". Revista Mal-Estar e Subjetividade, 8(3), 661-680. Link

Birman, J. (2007). Laços e desenlaces na contemporaneidade. Jornal de Psicanálise, 40(72), 47-62.

Birman, J. (2012). O sujeito na contemporaneidade: Espaço, dor e desalento na atualidade. Rio de Janeiro: Civilização Brasileira.

Buzyn, E. (2009). Je t'aime, donc je ne céderais pas: Accepter de poser des limites à l'enfant pour son plus grand bien. Paris: Bien-être.

Dufour, D-R. (2004). Télévision, socialization, subjectivation: Le rôle du troisième parent. Revue-le-débat, (132), 195-213. Link

Dufour, D.-R. (2005). A arte de reduzir as cabeças: Sobre a nova servidão na sociedade ultraliberal (S. R. Felgueiras, Trad.). Rio de Janeiro: Companhia de Freud.

Dunker, C. I. L. (2017). Intoxicação Digital Infantil. In Baptista, A. \& Jerusalinsky. J. (Orgs.). Intoxicações Eletrônicas: O sujeito na era das relações virtuais (pp. 117-145). Salvador: Ágalma.

Ferreira, M. G. (2015). Cultura Lúdica e Cultura Midiática na Contemporaneidade: O que as crianças pequenas revelam acerca desta relação. Poiésis: Revista do Programa de Pós-Graduação na Educação, Unisul, 9(15), 132-152. DOI: 10.19177/prppge.v9e152015132-152

Ferreira, T., \& Vorcaro, A. (2017). O tratamento psicanalítico de crianças autistas: Diálogo com múltiplas experiências. Belo Horizonte: Autêntica Editora.

Freud, S. (1996a). Estudos sobre a Histeria. In J. Strachey (Ed.), Edição Standard das Obras Psicológicas Completas de Sigmund Freud (Vol. 2, pp. 11-320). Rio de Janeiro: Imago. (Originalmente publicado em 1893-1895)

Freud, S. (1996b). A interpretação dos sonhos I. In J. Strachey (Ed.), Edição Standard das Obras Psicológicas Completas de Sigmund Freud (Vol. 4, pp. 157-168). Rio de Janeiro: Imago. (Originalmente publicado em 1899-1900)

Freud, S. (1996c). Três ensaios sobre a teoria da sexualidade. In J. Strachey (Ed.), Edição Standard das Obras Psicológicas Completas de Sigmund Freud (Vol. 7, pp. 119-231). Rio de Janeiro: Imago. (Originalmente publicado em 1905)

Freud, S. (1996d). Escritores criativos e devaneios. In J. Strachey (Ed.), Edição Standard das Obras Psicológicas Completas de Sigmund Freud (Vol. 9, pp. 133-143). Rio de Janeiro: Imago. (Originalmente publicado em 1908[1907])

Freud, S. (2006). Além do princípio do prazer. In Escritos sobre a psicologia do inconsciente. Obras Psicológicas de Sigmund Freud (Vol. 2, pp. 123-134). Rio de Janeiro: Imago. (Originalmente publicado em 1920)

Froede, C., Wollz, L. E. B., Sousa, P. M. S., de Sousa, T.R.S., \& Monteiro, G. A. (2014). Percepções de infâncias e do brincar na contemporaneidade. Humanas Sociais \& Aplicadas: Perspectivas online, 8(3), 23-34. DOI: 10.25242/887638201333

Han, B-C. (2017). Sociedade do cansaço (E. P. Giachini, trad.). Rio de Janeiro: Vozes. 
Jerusalinsky, J. (2017a). As crianças entre os laços familiares e as janelas virtuais. In A. Baptista \& J. Jerusalinsky (Orgs.), Intoxicações Eletrônicas: O sujeito na era das relações digitais (pp. 39-55). Salvador: Ágalma.

Jerusalinsky, J. (2017b). Atenção: Nem todo sofrimento psíquico na primeira infância é autismo, mas precisa ser tratado favorecendo a constituição. Correio, 266. Link

Kehl, M. R. (2013). Em defesa da família tentacular. Link

Lacan, J. (1938/2003a). Os complexos familiares na formação do indivíduo. In Outros Escritos (V. Ribeiro, trad., pp. 29-90). Rio de Janeiro: Zahar. (Originalmente publicado em 2001)

Lacan, J. (1961/2003b). Nota sobre a criança. In Outros Escritos (V. Ribeiro, trad., pp. 369-370). Rio de Janeiro: Zahar. (Originalmente publicado em 2001)

Martins, C. F. (2016). O brincar: Funções constitutivas e implicações das novas experiências tecnológicas. Dissertação de Mestrado, Instituto de Psicologia, Universidade de São Paulo, São Paulo. DOI: 10.11606/D.47.2016.tde-29092016-154656

Nicolaci-da-Costa, A. M. (2002). Revoluções tecnológicas e transformações subjetivas. Psicologia: Teoria e Pesquisa,18(2), 193-202. DOI: 10.1590/S0102-37722002000200009

Roudinesco, E. (2003). A familia em desordem (André Telles, trad.). Rio de Janeiro: Jorge Zahar.

Santos, C. C., \& Barros, J. F. (2018). Efeitos do uso das novas tecnologias de informação e comunicação para o desenvolvimento emocional infantil: Uma compreensão psicanalítica. Link

Tisseron, S. (2018). 3-6-9-12. Apprivoiser les écrans et grandir. Toulouse, France: ERES.

Trovão de Queiroz, M. T. (2019). Os Gadgets na Primeira Infância: Mudanças na Subjetividade e na Capacidade de Estar Só. Leitura Flutuante. Revista do Centro de Estudos em Semiótica e Psicanálise, 10(2). DOI: 10.23925/2175-7291.2018v1 $0 \mathrm{i} 2 \mathrm{p} 75-95$

Winnicott, D. W. (1975). O Brincar \& a Realidade (J. O. A. Abreu \& V. Nobre, Trad.). Rio de janeiro: Imago. (Originalmente publicado em 1971)

\section{Como citar:}

Mendes, E. D. (2020). Impasses na Constituição do Sujeito causados pelas Tecnologias Digitais. Revista Subjetividades, 20(Esp 2. O Contemporâneo à Luz da Psicanálise), e8984. http://doi.org/10.5020/23590777.rs.v20iEsp2.e8984

\section{Endereço para correspondência}

Elzilaine Domingues Mendes

E-mail: prof.elzilaine@gmail.com

Recebido em: 05/02/2019

Revisado em: 10/03/20120

Aceito em: 26/04/2020

Publicado online: $28 / 11 / 2020$ 